\title{
DINÂMICA DA INSERÇÃO DO DESIGN NO SETOR PÚBLICO POR MEIO DOS NÍVEIS DE INTERAÇÃO GRADATIVA: APLICAÇÃO DE INVESTIGAÇÃO DE INTERESSE DO GOVERNO MUNICIPAL
}

\author{
Malis Maria Liebl Keil \\ UFPR e Universidade do Contestado - UnC \\ malis.keil@gmail.com \\ Pâmela Quindani \\ Universidade do Contestado - UnC \\ pamelaqdn@hotmail.com \\ Virgínia de S. C. Borges Kistmann \\ UFPR e Pontifícia Universidade Católica do Paraná- PUCPR \\ vkistmann@ufpr.br
}

Resumo Em todo o planeta há um foco crescente de como o design e outras habilidades criativas podem contribuir no processo da rápida urbanização verificada ao longo das últimas décadas. 0 crescimento das cidades acelera a busca por soluções técnicas e sociais de design que possam atender ao desafio de criar ambientes urbanos sustentáveis em grande escala. No entanto, soluções de design vivenciadas por países desenvolvidos visando a superar falhas estruturais comuns na prestação de serviços e políticas ainda são inexistentes ou insípidas nas cidades do Brasil. Este artigo busca compreender a dinâmica da inserção do design no setor público e, com base nessas informações, propor um meio de aproximação entre o poder público municipal e designers no Brasil. A ação realizada alicerçou-se numa investigação de interesse do governo municipal de uma cidade do interior de Santa Catarina. A pesquisa foi realizada no contexto de um projeto de pesquisa abarcado na Universidade do Contestado, em parceria com a Prefeitura Municipal de São Bento do Sul. Esse trabalho conjunto deu-se por meio de questionários, aplicados em uma amostra populacional e que propiciou abordar diversos assuntos relacionados às percepções gerais sobre a qualidade de vida, qualidade da infraestrutura na cidade e participação nas decisões do município. Os resultados fazem parte de um conjunto de informações que indicam o nível de sustentabilidade do lugar e são divulgados na plataforma do Programa de Cidades Compactas da ONU (UN Global Compact Cities Programme). O principal resultado da ação foi a aproximação entre o governo e academia. Esta tem meios de realizar a pesquisa com estratégias de design (investigação com foco nos usuários finais), seguindo premissas do design (usuário é o centro) e envolvendo os diversos atores num objetivo comum (investigação participativa). A partir dos resultados obtidos foram indicadas as áreas de maior deficiência e interesse sob o ponto de vista da 
comunidade. Por outro lado, com essas informações, a academia, por meio do curso de Design, tem a possibilidade de propor projetos para soluções de problemas pontuais e que, consequentemente, abrem espaço para ações futuras.

Palavras-chave: Design, Design Thinking, Gestão do Design, Design para cidades.

Abstract: Worldwide there is a growing focus on how Design and other creative skills can contribute to the process of rapid urbanization seen over the past decades. The growth of cities accelerates the search for technical and social solutions design that can meet the challenge of creating sustainable urban environments in large scale. However, design solutions experienced by developed countries to overcome structural faults common in the provision of services and policies are still either nonexistent or insipid Brazilian cities. This article seeks to understand the dynamics of design insertion in the public sector in other countries and, based on this information; propose a means of rapprochement between the municipal government and designers in Brazil. The action taken was based on a research interest of the municipal government of a small city in the state of Santa Catarina, Brazil. Tindered by a research project sponsored by the Universidade do Contestado, in partnership with the city of São Bento do Sul. This joint effort took place by means of questionnaires served to a sample and that led to the addressing of several issues related to overall perceptions on the quality of life, quality of infrastructure in the city, and participation in municipal decisions. The results are part of a set of information that indicates the level of sustainability of the place and may be found in the UN Global Cities Programme. The main result of this action was the rapprochement between the government and academia. The latter has the means to carry out the research design strategies (research focusing on end users), following design assumptions (user is the center) and involving the various stakeholders in a common goal (participatory research). The results obtained were indicated the areas of greatest deficiency and interest in the community's point of view. Conversely, having this information, the academy, using Design, has the opportunity to propose projects for specific solutions to problems and thus make room for future actions.

Keywords: Design, Design thinking, Design management, Design for cities. 


\section{INTRODUÇÃO}

Dados das Nações Unidas (2014) apontam que em 2014, metade da população mundial era urbana e a previsão é de que em $2050,90 \%$ da população no Brasil será urbana. Desta forma, é necessário que as cidades possibilitem o acolhimento e propiciem meios de vida dignos a essa população. Esse mesmo estudo afirma que o crescimento não se dará devido à taxa de fertilidade da população urbana, mas decorrente de migrações do campo para a cidade e de mobilidade habitacional dentro de uma cidade. No Brasil, segundo dados do IBGE (Censo, 2000), a nova forma de estruturação do espaço urbano é caracterizada pelo processo de periferização das metrópoles brasileiras a partir dos anos 1970. O fenômeno ocorreu devido ao alto custo de se viver nas metrópoles, expressando, assim, o empobrecimento da população urbana. Os habitantes viram-se obrigados a se afastarem cada vez mais das grandes cidades. Este quadro das metrópoles brasileiras foi descrito pelo cientista político francês Touraine, "a miséria do país já não é mais rural, é urbana. O grande problema do Brasil é a destruição ou sobrecarga das grandes metrópoles" (TOURAINE, apud NOVAES, 2003, p. 24). Para reverter este quadro são necessárias reformulações na maneira de projetar para as cidades.

Para dar conta desse cenário territorial é necessário conjugar, religar e estreitar relações entre o lugar e os atores envolvidos no processo de pertencimento a esse lugar. A colaboração desses atores é ativa neste contexto e o design é o meio pelo qual essas informações são articuladas e organizadas de modo a fazer sentido (GOSPODINI, 2004).

No âmbito do design, projetar para cidades implica no entendimento das múltiplas necessidades coletivas, o que torna a questão complexa e exige a aplicação de ferramentas e técnicas que auxiliem na coleta, análise e solução de problemas.

Como inserir o design em projetos urbanos, área usualmente ocupada pela arquitetura e urbanismo?

Inicialmente devem-se considerar as seguintes questões apontadas pelo estudo Design for Public Good, do Design Council (2013), as quais justificam que a prestação de serviços do setor público tradicional e elaboração de políticas públicas, encontra uma série de obstáculos atendidos pelo design.

Quadro 1 - Comparação entre projetos do setor público executados sem e com a participação do design.

\begin{tabular}{|l|l|}
\hline PROJETOS DO SETOR PÚBLICO TRADICIONAL & PARTICIPAÇÃO DO DESIGN \\
\hline $\begin{array}{l}\text { Incrementalismo desarticulado } \\
\text { Isso significa que o governo gasta muito; } \\
\text { combate incêndios constantemente; remenda } \\
\text { soluções aparentemente convenientes que } \\
\text { reprojetam o que já existe, sem parar para } \\
\text { perguntar se os fundamentos são reais. Muitas } \\
\text { vezes, o motorista seria o corte de custos, mas, } \\
\text { se as necessidades reais não forem cumpridas, } \\
\text { a poupança é uma falsa economian }\end{array}$ & $\begin{array}{l}\text { Projetando para } \\
\text { Designers reformulam a questão em termos e } \\
\text { condiçes do mundo real dos serviços e das } \\
\text { políticas que procuram atender. Eles olham para } \\
\text { as necessidades das pessoas em soluções de } \\
\text { perguntas e adaptam em conformidade. }\end{array}$ \\
\hline $\begin{array}{l}\text { Projeto Piloto de alto risco } \\
\text { Novas medidas do governo são } \\
\text { frequentemente executadas em projetos piloto } \\
\text { e em escalas muito grandes, o que faz que }\end{array}$ & $\begin{array}{l}\text { Processo de design testa soluções com baixo } \\
\text { custo, inicialmente em protótipos de pequena } \\
\text { escala. Ela vê a falha nesta fase como "fracasso }\end{array}$ \\
\hline
\end{tabular}




\begin{tabular}{|c|c|}
\hline incorram em riscos e custos consideráveis. & $\begin{array}{l}\text { inteligente" que permite melhorar as soluções e } \\
\text { reduzir o risco, com protótipos progressivos. }\end{array}$ \\
\hline $\begin{array}{l}\text { Falta de reflexão conjunta } \\
\text { Como os governos estão começando a } \\
\text { reconhecer a desconexão entre a análise de } \\
\text { problemas, criação de soluções e } \\
\text { implementação para que não haja ineficiência. }\end{array}$ & $\begin{array}{l}\text { Um processo de inovação completa } \\
\text { Projeto que leva à inovação, é um processo que se } \\
\text { move continuamente da análise até a } \\
\text { implementação. }\end{array}$ \\
\hline $\begin{array}{l}\text { Falta de envolvimento dos cidadãos } \\
\text { Este é um problema por dois motivos: se os } \\
\text { cidadãos não foram consultados sobre o } \\
\text { serviço e política de inovações, não há } \\
\text { nenhuma garantia de que suas reais } \\
\text { necessidades serão atendidas e eles estão } \\
\text { menos propensos a comprar para eles quando } \\
\text { há uma imposição. }\end{array}$ & $\begin{array}{l}\text { Um processo centrada no cidadão } \\
\text { Design começa por identificar as necessidades do } \\
\text { usuário e passa a trabalhar com os usuários ao } \\
\text { longo do processo de co-design e de soluções } \\
\text { testadas. Isto significa que o que ele oferece não } \\
\text { só funciona para as pessoas afetadas, mas que } \\
\text { estas pessoas possuem e promovem as novas } \\
\text { medidas. }\end{array}$ \\
\hline
\end{tabular}

Fonte: Adaptado de Design Council, Design for Public Good, 2013, pp. 18-19.

Considerando essas questões, foi elaborada pelas entidades UK Design Council, Danish Design Centre, Design Wales e Aalto University (Finlândia), em 2013, uma estratégia de abordagem para o setor público, em projetos que não eram, necessariamente, objetos físicos, podendo ser realizados por meio de serviços ou de políticas públicas. A atuação é dividida em três níveis de interação gradativa, chamada de The Public Sector Design Ladder, apresentada na Figura 1.

Essa ferramenta desenvolvida para a Comissão Europeia "deveria promover a utilização da escada e do fundo de trabalho de desenvolvimento como uma ferramenta de diagnóstico e roteiro para a progressão". E assim, "criar um quadro mais detalhado do uso e eficácia das capacidades de design e disciplinas afins em cada degrau da escada" (DESIGN COUNCIL, 2013, p. 17).

Figura 1 - The Public Sector Design Ladder

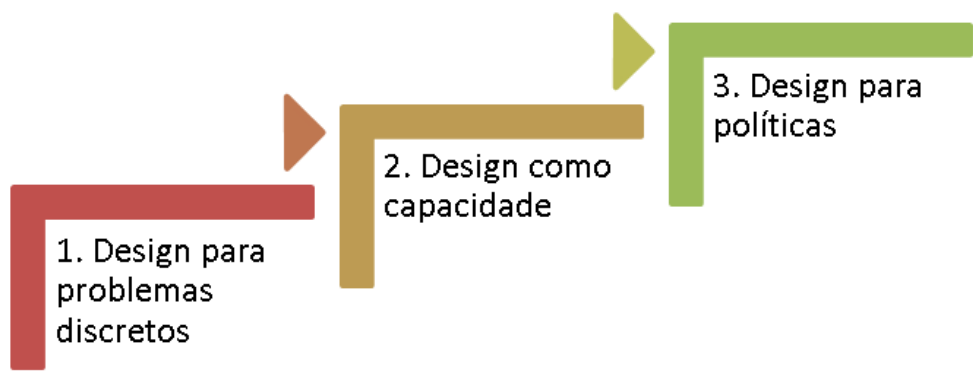

Fonte: Adaptado de Design Council, Design for Public Good, 2013, p. 8.

Os níveis se distribuem de tal forma que no primeiro, as equipes de design são contratadas para projetos individuais abordagem de problemas pontuais. Pequenas soluções, normalmente para nível operacional, mas que abrem espaço para ações futuras.

No segundo nível o design torna-se parte da administração pública, auxiliando a compreender e tomar decisões baseadas no design thinking. Como exemplo, repensar plataformas de serviços oferecidos pela prefeitura de Londres para adequar às necessidades e urgências dos usuários do sistema.

No terceiro nível, o design thinking é utilizado pelos gestores responsáveis pela 
elaboração das políticas como estratégia, onde os designers atuam como facilitadores, "para superar os problemas estruturais comuns na definição de políticas tradicionais" (DESIGN COUNCIL, 2013, p. 17).

Esse estudo europeu serviu de inspiração para projetar ações de aproximação entre academia, designers e governo municipal no Brasil. Para a concretização desse objetivo, buscaram-se áreas de mútuo interesse, onde a academia pudesse realizar alguma ação em design. Das inúmeras áreas possíveis de atuação, optou-se por ações direcionadas à sustentabilidade, onde já havia uma sensibilização entre os atores.

Havia em curso uma parceria entre academias (Universidade do Contestado- UnC e PUCPR), entidade governamental (Consórcio Intermunicipal do Quiriri - $\mathrm{CIQ}$ ) e governos municipais integrantes do $\mathrm{CIQ}$, para a realização de um diagnóstico sobre a sustentabilidade na região.

\section{O PROJETO ESCOLHIDO}

Buscou-se uma metodologia que atendesse as necessidade de diagnosticar e apontar quais são as reais necessidades e anseios da população de um território urbano. Para tanto, inicialmente, pesquisou-se junto à Organização das Nações Unidas - ONU, a metodologia do Programa de Cidades Compactas da ONU que tem como referência os dez princípios do Pacto Global. Esse programa, de amplo espectro, parte da premissa de que as cidades tem a capacidade de resolver os problemas enfrentados por ela e regiões do entorno, se focados na colaboração entre todos os níveis de governo, organizações privadas e sociedade civil, de forma a combinar ideias, conhecimento, experiência e recursos existentes nos três setores.

No desdobramento da pesquisa optou-se pela metodologia específica para diagnóstico e avaliação da sustentabilidade de áreas urbanas, denominada "Círculos da Sustentabilidade" (JAMES, 2015).

Essa metodologia utiliza diversas ferramentas e técnicas que permitem desenvolver uma descrição interpretativa da sustentabilidade de uma região urbana e seus arredores. Nela a sustentabilidade é entendida em relação aos processos locais, nacionais e globais: ecológicos, econômicos, políticos e culturais. Uma das técnicas utilizadas no diagnóstico dos Círculos da Sustentabilidade é a aplicação de um questionário cujo objetivo é compreender, de forma mais abrangente, um território urbano. A partir das respostas do questionário é realizada uma representação gráfica simples do perfil de sustentabilidade desta região.

Os resultados obtidos com essa pesquisa possibilitaram identificar eixos de interesse da comunidade e quando apresentadas ao governo municipal, permitiram priorizar os investimentos de forma a aumentar o bem estar da população.

Neste contexto o design atua estrategicamente, como uma ferramenta de desenvolvimento social, econômico, industrial e territorial, de forma a auxiliar no planejamento e projeto das cidades. O design, nesse momento, atua como interlocutor entre os atores, aproximando-os e sugerindo soluções em serviços, o que caracteriza o primeiro 'degrau' do The Public Sector Design Ladder, Figura 1.

\subsection{A abordagem metodológica dos Círculos da Sustentabilidade}

A abordagem dos Círculos da Sustentabilidade iniciou em 2007, junto ao Programa das Cidades Compactas das Nações Unidas, Pacto Global das Cidades, em Melbourne (Austrália) e em Nova York (EUA), e vem sendo refinada ao longo dos 
últimos 9 anos. O objetivo dessa abordagem é alcançar a sustentabilidade e resiliência em cidades, comunidades ou organizações, combinando indicadores qualitativos e quantitativos, sempre de forma adaptável às realidades locais.

Essa abordagem propõe ferramentas a quatro questões chave, distribuídas em quatro eixos temáticos, denominados pelo autor, James (2015), como domínios: econômico, ecológico, político e cultural. Todos estes são domínios da vida social e são fundamentados na vida real, exercidos cotidianamente nas práticas sociais e na formação de significado. Para tanto, é necessário o engajamento da comunidade na avaliação de cada domínio, identificando as potencialidades e apontando as deficiências do lugar.

Figura 2 - Circles of Social Life, Círculos da sustentabilidade.

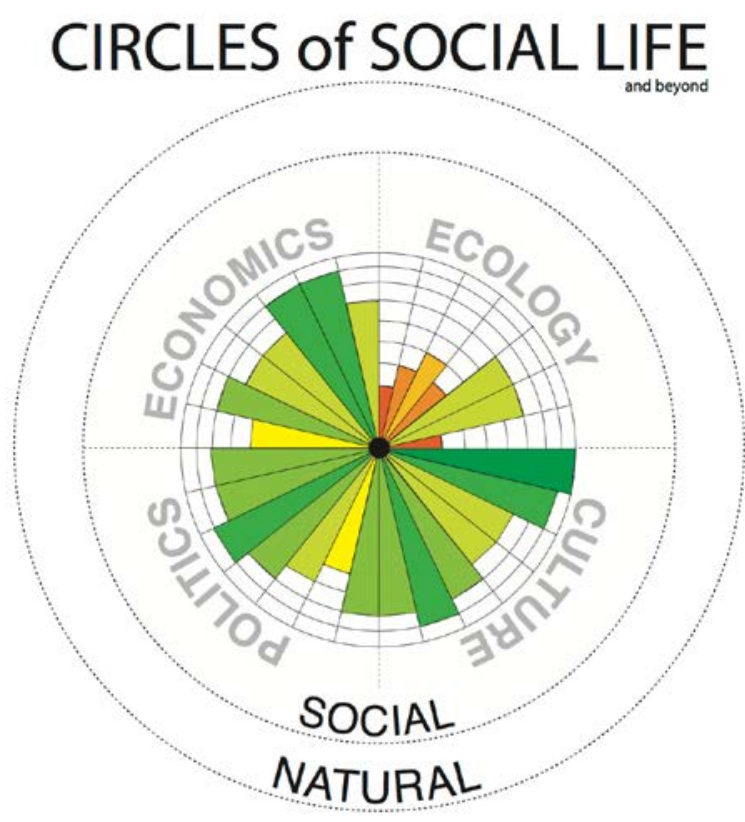

Fonte: AdaptadoldẹAMES ẹtläl:. 2015,0p.14.

ECONOMICS ECOLOGY

Os is princípios envolvidos nà questão têm como objetivo em comum analisar e definir dados sobre as variadas áreas em uma sociedade, que interferem diretamente no desenvolviment gên

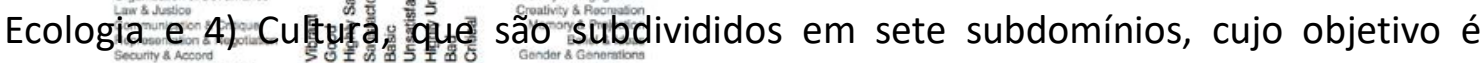
identificar, compreender erresponder a questões críticas.

Sobre a política o projeto buscou obter resultados sobre a forma de governo da região, demonstrando o retorno que a população recebe na área que vive, através da forma de administração dos bens públicos, monitoramento do local e o planejamento para o desenvolvimento da região, para que isso ocorra é indispensável a transparência nos atos sociais. Este tópico do projeto buscou informações visando a igualdade entre todos, assim como os direitos e deveres de ambos, sendo governantes ou população. É importante ressaltar a democracia, liberdade e inclusão de todos, gerando assim respeito, confiança e segurança.

$\mathrm{Na}$ Ecologia, foram tabulados os atributos do local, como a fertilidade do solo, metais e minerais; a exploração de energias renováveis e recicláveis da região; aspectos sobre a água, como sua qualidade e consequente potabilidade; 0 ar, gases do 
efeito estufa e do carbono. A flora e a fauna foram avaliadas ressaltando sua biodiversidade e analisando os ambientes preservados. A maneira que as pessoas se locomovem interfere diretamente na ecologia, considerando as áreas pavimentadas e aeroportos. A média de idade da população, assim como a qualidade de vida, índices de poluição e resíduos, também foram levados em consideração.

$\mathrm{Na}$ Economia, os níveis de extração e colheita dos produtos assim como a influência da arte e do design no local foram avaliados. Recursos humanos e físicos disponibilizados à população foram critérios contribuintes para a média final da região, incluindo os bens e serviços, impostos, comércios, turismo, dívidas, taxas de emprego e desemprego, níveis de saúde e segurança, qualidade da educação e saúde.

Já a Cultura, representou a diversidade, avaliou a comunidade em geral, ressaltou as variadas etnias, idiomas e religiões. Consideraram festas e costumes, inovação cultural e opções de lazer. Tabulou-se o patrimônio histórico e indicaram-se seus registros. Analisou-se as famílias, índices de mortalidade e desenvolvimento populacional, qualidade de ensino, níveis de conclusão e formação de estudantes.

A abordagem parte de um questionário social com questões que cobrem os quatro domínios, avaliando a natureza da vida social do lugar, que são os itens a seguir:

\& A prosperidade econômica - na medida em que a comunidade pode se envolver em atividades relevantes para o seu bem-estar econômico e se sentir confiante sobre a consequência da alteração das estruturas para além da sua localidade.

\& Resiliência ecológica - a medida em respondentes perceberam as "taxas" em que o ambiente natural envolvente pode resistir e se recuperar de ações da comunidade.

\& Engajamento político - na medida em que os membros da comunidade podem participar e colaborar em processos e estruturas de poder que lhes dizem respeito.

\& Vitalidade cultural - na medida em que a comunidade é capaz de manter e desenvolver suas crenças, comemorar suas práticas e rituais, e cultivar narrativas de sentido que definem a comunidade.

Os resultados do questionário forneceram um contexto útil para examinar a relação entre a alternativa subjetiva, intersubjetiva e modos objetivos de medição; entre os indivíduos e comunidade; e entre o presente bem-estar e sustentabilidade futura. Sob o ponto de vista da comunidade.

\section{PROCEDIMENTO METODOLÓGICO}

Esta pesquisa resulta da aplicação de questionário, tabulação dos dados e posterior avaliação estatística, a fim de elencar as percepções da comunidade a respeito da sustentabilidade em cada bairro do município. O questionário está disponível em open access no site dos Círculos da Sustentabilidade ${ }^{1}$ e a aplicação contou com a orientação técnica da PUCPR, por meio do Centro de Inovação.

O projeto de pesquisa contou com o apoio da Prefeitura Municipal de São Bento do Sul e da Secretaria de Educação e do Consórcio Intermunicipal do Quiriri. A

\footnotetext{
${ }^{1}$ http://www.circlesofsustainability.org/
} 
Secretaria de Educação mobilizou os diretores de escolas e creches municipais e em reunião geral foi apresentado o projeto dos Círculos da Sustentabilidade, objetivos, resultado esperado e posteriormente foram distribuídos os questionários para que fossem respondidos por membros do bairro, preferencialmente, membros das associações de pais das escolas. Nessa amostra não foram consideradas as localidades rurais do município, pois delas não havia representante.

Figura 3 - Localização do município de São Bento do Sul e mapa dos bairros do município.
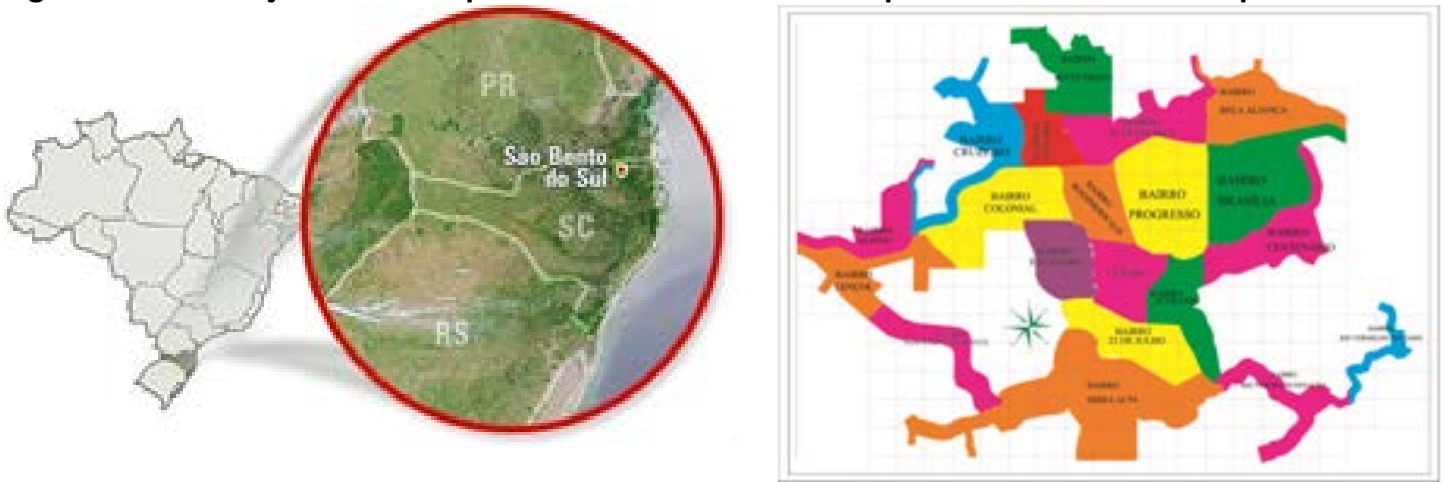

Fonte: imagem da esquerda http://beutherluminosos.com.br/localizacao.php, imagem da direita adaptado de http://www.saobentodosul.sc.gov.br.

Foram respondidos 173 questionários moradores dos 20 bairros do município, correspondendo a $0,25 \%$ da população do município.

Tabela 1: Relação de bairros e, população do município de São Bento do Sul, questionários respondidos e percentual em relação à população.

\begin{tabular}{|c|c|c|c|}
\hline Bairros (20) & $\begin{array}{l}\text { № questionários } \\
\text { respondidos }\end{array}$ & $\begin{array}{l}\text { População do } \\
\text { bairro (ANO 2007) }\end{array}$ & Proporção \\
\hline 25 de Julho & 16 & 5748 & $8 \%$ \\
\hline Alpino & 8 & 1419 & $2 \%$ \\
\hline Bela Aliança & 2 & 311 & $0,4 \%$ \\
\hline Boehmerwald & 5 & 2136 & $3 \%$ \\
\hline Brasília & 8 & 7041 & $9,7 \%$ \\
\hline Centenário & 13 & 5008 & $7 \%$ \\
\hline Centro & 9 & 4945 & $6,8 \%$ \\
\hline Colonial & 14 & 7339 & $10 \%$ \\
\hline Cruzeiro & 16 & 6792 & $9,3 \%$ \\
\hline Dona Francisca & 5 & 2049 & $2,8 \%$ \\
\hline Industrial Sudoeste & 0 & 66 & $0,1 \%$ \\
\hline Lençol & 7 & 1380 & $1,9 \%$ \\
\hline Mato Preto & 9 & 2668 & $3,7 \%$ \\
\hline Oxford & 8 & 3550 & $4,9 \%$ \\
\hline Progresso & 9 & 3267 & $4,5 \%$ \\
\hline Rio Negro & 6 & \multicolumn{2}{|c|}{ Sem dados } \\
\hline Rio Vermelho Estação & 7 & \multirow[t]{2}{*}{1207} & \multirow[t]{2}{*}{$1,7 \%$} \\
\hline Rio Vermelho Povoado & 4 & & \\
\hline Schramm & 8 & 4193 & $5,8 \%$ \\
\hline Serra Alta & 19 & 10647 & $14,7 \%$ \\
\hline Localidades (9) & & 2782 & $3,8 \%$ \\
\hline Total & 173 & 72.548 & $100 \%$ \\
\hline
\end{tabular}

Fonte: Elaborado pelas autoras, com base na pesquisa realizada. 
As perguntas buscaram de forma objetiva e de fácil entendimento, a opinião da população sobre variados assuntos decorrentes do dia a dia. Os dados identificados e tabulados demonstraram a satisfação ou insatisfação da população sobre assuntos diversos.

As perguntas buscaram a opinião do cidadão sobre a comunidade em que vive, o ambiente físico, a qualidade da saúde e a educação, participação nas decisões da comunidade, infraestrutura do bairro, resolução dos problemas ambientais e públicos, e, tomada de decisões.

Incluem também a visão geral da pessoa em relação à cidade e não só de seu bairro, como a política na sua totalidade e influência na região; mudanças ocorridas no ambiente, alterações climáticas; falta de recursos como água e energia; crises econômicas e a influência da cultura sobre a vida do lugar.

Outra sessão engloba a opinião sobre a era tecnológica atual e suas inovações, qualidade e identificação com o ambiente de trabalho, liberdade de expressão, distribuição e acesso de todos em relação a parques, escolas e postos de saúde, desenvolvimento e preservação ambiental, convivência e inclusão de diferentes culturas.

O questionário também teve seu foco em questões sobre, percepção de segurança na comunidade, manutenção de ruas e praças, pontos de ônibus, disponibilidade e locais para exercícios físicos.

Ao final, o participante respondeu duas perguntas discursivas, a primeira pergunta, sobre a satisfação e identificação dos pontos mais favoráveis e preferidos do local onde mora, e, a segunda, sobre pontos a melhorar.

Esse material coletado passou pela tabulação e tratamento estatístico, de onde foram extraídos os macros resultados apresentados na sequência.

\section{RESULTADOS DA PESQUISA}

Os resultados da pesquisa mostraram que a $90 \%$ população considera-se feliz na comunidade em que mora, $87 \%$ afirma estar satisfeito em fazer parte da comunidade e $66 \%$ afirma que estar na comunidade é o que mais the agrada. Comprovando que as pessoas que responderam os questionários mantém relações afetivas com o lugar.

A comunidade para $40 \%$ dos entrevistados é estar em seu lar, para $23 \%$ é o seu ambiente de trabalho, $15 \%$ é a comunidade religiosa, os relacionamentos com um grupo específico de pessoas define a comunidade para 5,7\% e, a comunidade cultural e política foi a resposta de $5 \%$.

$57 \%$ dos entrevistados consideram-se protagonistas e influenciados de valores e modos de vida na comunidade. O poder de influência sobre as decisões tomadas por pessoas ou instituições que comandam a comunidade considerada verdadeira por $35 \%$ e falsa por $33 \%$. O que leva à próxima questão, $45 \%$ demonstram insatisfação com as decisões tomadas para a comunidade onde ela não está opinando, 35\% está satisfeita, enquanto $20 \%$ é indiferente. Conclui-se que mesmo que a comunidade sinta-se responsável pelos assuntos comunitários, que pode influenciar nos resultados, tem a percepção de sua opinião nem sempre é considerada.

Em dados gerais, a comunidade tem convicção sobre a liberdade pessoal, de religião, de pensamento ideológico e político, no entanto aponta uma preocupação com a falta de segurança, limpeza, iluminação e conservação de espaços públicos 
como praças, ruas, parques. Em especial nas comunidades mais afastadas ou com grande população, onde a qualidade de vida não acompanhou o desenvolvimento do lugar. As entrevistam apontam que esses bairros sofrem com falta de infraestrutura, equipamentos públicos e deficiência em mobilidade. Há uma generalizada percepção de corrupção das organizações municipais, estaduais e nacionais, 94\%. A falta de credibilidade que o governo municipal para a resolução dos problemas da comunidade, foi apontado por $52 \%$, no entanto, $20 \%$ se diz indiferente.

Quando perguntados sobre as inovações tecnológicas, 79\% dos entrevistados acredita que a tecnologia (celular, internet) trouxe maior liberdade, porém $89 \%$ estão preocupados com a influência da globalização nos aspectos da vida familiar e da preservação da cultura local. Quando perguntados sobre a cultura, 68\% dos entrevistados percebem a decadência de instituições da cultura local.

Os entrevistados estão preocupados com as questões: climáticas (95\%), econômicas (88\%), políticas e guerras (90\%) e ambientais como água e energia (81\%). Dados que confirmam que essas pessoas estão interessadas e informadas. No entanto, $52 \%$ dos pesquisados não acredita que o crescimento econômico é compatível com a sustentabilidade ambiental.

Nas questões sobre a sustentabilidade social, não foram apontados problemas de relacionamento interpessoal, nem dificuldade de aceitar novos moradores, nem dificuldade de acesso à locais de ensino, saúde, recreação e prece, pois esses estão bem distribuídos na comunidade, permitindo o acesso a todos. No entanto, nem sempre foi encontrado o profissional de saúde no local em $25 \%$ dos entrevistados.

\section{CONSIDERAÇÕES FINAIS}

O principal objetivo da pesquisa foi promover a interação entre a academia e governo municipal. Não objetivou unicamente a aplicação dos questionários, mas promover a interlocução, uma vez que não é usual o governo municipal consultar os munícipes para identificar possíveis demandas. Essa faz parte da prática habitual no design, onde o usuário é fator relevante das decisões projetuais.

Para tanto, se buscou uma metodologia que apoiasse a integração entre os atores, ao mesmo tempo em que explicasse as relações entre eles e as vantagens de se utilizar a metodologia do design para a resolução de problemas municipais. Na questão da dinâmica de inserção do design no setor público, a The Public Sector Design Ladder (DESIGN COUNCIL, 2013), atendeu aos propósitos, pois permitiu às pesquisadoras identificar a forma de intervenção de design que poderia ter maiores chances de obter sucesso. Na problemática da explicitação ao setor público das vantagens do uso de design num projeto público, o quadro comparativo entre projetos do setor público executados sem e com a participação do design, também elaborada pelo Design Council, mostrou-se clara e precisa, na realidade do município alvo da pesquisa.

A motivação do governo local para a realização de uma pesquisa sobre a sustentabilidade foi crucial para que houvesse uma real integração. A estratégia abordada pelas designers foi em relação à organização das etapas, a forma de abordagem dos articuladores para a distribuição dos questionários, recolhimento após o preenchimento e tabulação dos resultados, apresentação dos resultados ao governo municipal para posterior divulgação no site das Cidades Compactas da ONU.

A dúvida inicial do governo municipal era em relação ao interesse da população para o preenchimento do questionário. Mas ficou evidente ao longo dos resultados da 
pesquisa, que os moradores desejam participar das decisões sobre projetos e futuras ações, porém não encontram um canal de comunicação que leve os interesses da comunidade ao governo.

Por outro lado, a mobilização dos parceiros demonstrou que há interesse por parte do governo em colaborar com pesquisas que tragam resultados concretos para ações de planejamento municipal. No entanto, costumeiramente, o governo não protagoniza essa ação, por não dispor de pessoal ou capacidade técnica para a execução das pesquisas.

Diante disso, conclui-se que é viável a participação do design nesse tipo de mobilização, pois dispõe de ferramentas e técnicas que tem por resultado a aproximação dos atores, promove a comunicação articulada entre eles, buscando formas de acessar o maior número de pessoas propensas a colaborar. Esses articuladores operacionais, nesta pesquisa, eram professores, gestores de escolas e participantes das associações de pais nas mesmas.

Como resultado final constatou-se que a maior contribuição na área do design foi demonstrar ao poder público municipal que o design pode colaborar em projetos urbanos, com pequenas soluções no nível operacional, mas que abrem espaço para outras. Por outro lado, as informações coletadas são grande arcabouço de ideias para futuros projetos de design a serem desenvolvidos em parceria entre a academia, 0 governo e, talvez, o setor privado.

\section{AGRADECIMENTO}

O presente trabalho foi realizado com apoio do Programa de Bolsas Universitárias de Santa Catarina - UNIEDU

\section{REFERÊNCIAS}

ASSOCIAÇÃO EMPRESARIAL DE SÃO BENTO DO SUL. Perfil socioeconômico: São Bento do Sul. São Bento do Sul: UNIVILLE, 2009. 126 p.

BRASIL, I. B. G. E. Instituto Brasileiro de geografia e Estatística. Censo Demográfico 2000, 2008.

BRASIL, I. B. G. E. Instituto Brasileiro de geografia e Estatística. Dados do município de São Bento do Sul, SC. Disponível em <http://www.cidades.ibge.gov.br/xtras/perfil.php?lang=\&codmun=421580\&search=|| infogr\%E1ficos:-informa\%E7\%F5es-completas>. Acesso em 30 de abr 2016.

DESIGN COUNCIL. Design for Public Good. London: Design Council, May /2013. SEE Platform. Londres, 2013. Disponível em < http://www.designcouncil.org.uk/resources/report/design-public-good>. Acesso em 30 abr 2016.

GOSPODINI, Aspa. Urban morphology and place identity in European cities: built heritage and innovative design. Journal of Urban Design, v. 9, n. 2, p. 225-248, 2004. JAMES, Paul et al. Urban Sustainability in Theory and Practice: Circles of sustainability. Nova York: Routledge, 2015. 260 p.

NOVAES, Washington. VIVER NAS CIDADES. In: NETO, E. R.; (ORGS.), C. M. B. Saúde 
nos aglomerados urbanos: uma visão integrada. Brasilia: Organização Pan-Americana da Saúde, 2003. p. 21-39.

UNITED NATIONS. World Urbanization Prospects. New York: United Nations, 2015.

Disponível em < http://esa.un.org/unpd/wup/Publications/Files/WUP2014-Report.pdf >. Acesso em 30 de abr 2016. 